\title{
Effects of the Workplace Game: A Case-Study into Anticipating Future Behavior of Office Workers
}

\author{
Annelise de Jong ${ }^{1}$, Merlijn Kouprie ${ }^{1}$, and Evi De Bruyne ${ }^{2}$ \\ ${ }^{1}$ Delft University of Technology, Faculty of Industrial Design Engineering \\ Landbergstraat 15, 2628 CE Delft, The Netherlands \\ ${ }^{2}$ Center for People and Buildings, \\ Kluyverweg 6, 2629 HT Delft, The Netherlands \\ \{A.M.deJong, E.deBruyne\}@tudelft.nl, merlijnkouprie@gmail.com
}

\begin{abstract}
This paper describes the evaluation of the Workplace Game regarding the type of information that it provides. The Workplace Game is intended to make employees aware of the changes in the office and the implications thereof on their behaviour and way of working. The game might also be helpful for designers or architects of future flexible offices. To find out what type of information the game provides and if the information can be of use for designers the game was evaluated in an observational study of two playing sessions. The study showed that the Workplace Game stimulates employees to talk about their behaviour. The game makes players talk about their future work behaviour by eliciting information about their present work behaviour. However, the game needs adaptation to provide directions for designing future flexible offices. Recommendations how the game can be made helpful to designers of future flexible offices are discussed.
\end{abstract}

Keywords: flexible office, participatory design game, empathic design, user experience, office layout, innovative office design, office behaviour.

\section{Introduction}

In modern society the needs of organizations change, not only in terms of internal economic growth but also due to the dynamic environment that they are a part of. It is essential to be able to adapt the workspace to these changing needs to support people in carrying out their activities, for instance in a proper exchange of knowledge when workers are dislocated. This adaptation of workspace often does not only entail a physical change of the office environment, but involves also a social change in people's ways of working.

More and more Dutch companies change their existing office environment into an environment that is designed to stimulate flexibility, adaptation and social interaction. Office innovation often is a radical change and its success is largely dependent on the ways people are able to adapt to this new work environment, especially on the ways people are willing to adapt and committed to the change. Often, the failure of such a change is due to the fact that employees are not sufficiently involved in the creation of this new flexible office. They are not consulted on their present working behaviour or 
asked to elaborate on their views of this future office environment. This makes them feel disengaged, which strongly influences their willingness to adapt to the new work environment.

To engage people more into the process of changing the office environment, the Center for People and Building developed The Workplace Game. This game is in essence a communication tool that enables office workers to exchange ideas about their (future) office environment and clarifies future implications of the changes. It consists of a game board that is designed to resemble an office floor plan, and a set of playing cards with multiple-choice questions that are divided into three categories: workplaces, meeting places, and facilities. Since the Workplace Game is designed to make employees have an open discussion about their office environment, the information it generates could be helpful for office space designers or architects, in the way that it could provide them with (future) behavioural information about the office workers [4].

This paper evaluates the Workplace Game in terms of the information that it provides for office space designers. We evaluate what type of information about work behaviour (in future flexible offices) the Workplace Game elicits and draw conclusions for its potential use in designing future flexible office spaces.

\section{The Workplace Game}

In two previous articles the Workplace Game and its elements are explained in detail [3]. Here we will shortly summarise the goal of the game and introduce the case studies that were analysed in the present research.

\subsection{Goal}

The Workplace Game is a tool to facilitate user involvement in the implementation and management of innovative offices. It is developed as an evaluation tool to make employees aware of the changes in the office and the implications thereof on their way of working. When companies introduce a new office concept it is not enough to merely introduce the workers to this environment. Office users will need time to adapt to the new work situation, change and learn new behaviours that fit the new office situation. Simply telling the users what to do and how to react to the new situation often does not lead to the desired working behaviour. The Workplace Game facilitates broad user involvement in the process of change and helps people to prepare for and adapt to the future situation.

The game has five goals: (1) it stimulates awareness of employees about the changes (to come) in the work environment, (2) it stimulates discovering of and discussion on new desired behaviour, (3) it creates awareness of employees about their own points of view, (4) it stimulates the development of shared values and norms, and (5) it creates input for the development of rules of conduct for the new situation. Using the game to provide input for a design process was not a consideration when it was first developed.

The Workplace Game is aimed at the user (to be) of an innovative office environment and can be played before, during or after the implementation of the new context. One precondition is that the employees must have experience with, rather than knowledge of, flexible offices. The most important ingredients of the game are the questions, 
which state rather down-to-earth situations and workers' responses to it. Each question is assigned to one of the following themes: information \& knowledge, attitude $\&$ behaviour, and values $\&$ norms, which reflects loosely the layer theory of organisational culture of Schein [3].

\subsection{Case Studies}

We analyzed two case studies in which the Workplace Game was played. Both were executed in one company that was about to change their existing office structure into a more dynamic structure, thus it was a scenario that was actually happening for the employees of the company and not just a simulation. The Workplace Game was played with the intention of introducing workers to their future working situation. We provided them with materials and guidelines to do so, and at the same time allow us to evaluate the game. Each study contained multiple groups, and each group consisted of several (3 to 5) employees. Before playing the game there was a short introduction, explaining the goal and the rules. The game ended after approximately one hour of playing, and afterwards there was a group discussion. We consider the discussion as part of the Workplace Game, because it forms a significant part of the game where shared values and norms can be created with the entire group. The two studies that we observed differed from each other: In the first session the choice of an innovative flexible office concept was presented without illustration of specific floor plan details, whereas in the second session the architect gave a detailed presentation of the future flexible office. In this paper we analyse both case studies, trying to discover the experiences of the players regarding future flexible offices.

\section{People's Experiences}

The experiences that people have are unique for each individual. If we can access those experiences we can use them as information and inspiration for designing new products and services. To study these experiences several methods can be applied [6].

Sanders and Dandavate [9] discussed the main issues designers have to deal with when trying to access these user experiences in terms of knowledge. People have explicit knowledge, which is knowledge on which they can inform us, because they are able to express this knowledge in words. Designers should listen to what users tell about their past experiences in interviews, however, they should be aware that the user could leave out significant details. Furthermore, designers can look at what people do, which provides them with observable information. Designers should look at how people behave and how they use products. Again, however they should be aware that significant information could be missing; one can only observe present behaviour, not future behaviour or needs. To truly understand people's experience a designer needs to gain a deep understanding of users and empathize with them [5]. Understanding how people feel provides the designer with tacit knowledge, knowledge that users cannot express in words, but that is of great importance to the designer. It reveals latent needs that can only be recognised in the future. Generative techniques enable us to reveal people's knowledge, feelings and dreams for the future. Figure 1 shows the relationships between the various techniques of gathering data described, and their ability to access these knowledge levels [10]. 


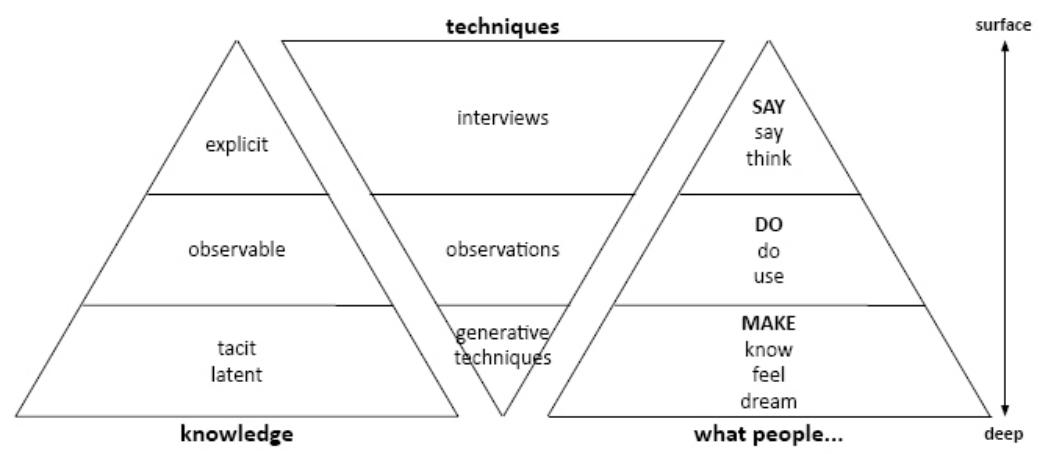

Fig. 1. Different levels of knowledge about experience are accessed by different techniques

\subsection{Empathic Design Techniques}

Truly understanding people's behaviour and intentions is difficult. Now that we are aware what layer of user knowledge we need to reach to get to know people's dreams for the future, the question is how we can reach this layer, and whether the Workplace Game could be used to obtain access to it.

Empathic design aims to "provide designers access to how users experience their material surroundings and the people in it, including themselves as key characters of their everyday lives" [7]. Techniques within the field of empathic design, such as generative techniques, often succeed in reaching the deeper levels of user experiences. What these techniques have in common is that they are primarily visual and focus on the creativity of a user, which serves as a common ground for connecting people from different disciplines. A designer can use empathic design techniques to explore the user's life and to gain a deeper understanding of this life. Next to this, the designer is also inspired to imagine new and better possibilities for people. This inspiration can be used to create more useful and enjoyable things for people [5].

According to this theory Sanders [8] developed the 'Make Tools', which facilitate exchange between people who experience products and the people who design for experiencing. The user is given a playful assignment around a certain theme and is asked to create something out if this, in a safe environment. By having users make artefacts and by asking them to tell stories about it they will be able to express their thoughts, feelings, and dreams for the future. The aim of the present study is to reveal whether the Workplace Game provides the designer with a deeper understanding of the user by accessing his or her latent needs, and if so, if the Workplace Game can be used as inspiration for designing new flexible offices.

\section{Evaluating the Workplace Game}

In the study presented here, we did a qualitative analysis of the game. We observed two sessions and compared the results in our analysis. Our aim was to gain an understanding of what type of information about working behaviour (in future flexible offices) the Workplace Game elicits. The main research questions were: do players talk 
about past, present, and/or future behaviour? And, do players talk about their preferences for their future flexible office? For the analysis we observed players and their utterances during the two sessions of the workplace game.

\subsection{The Sessions}

Session 1 - Results of the observations. The participants are very open when they start playing the game. It is explained that playing the game is about creating awareness about the workplace and their behaviour in it. One participant expresses her worries in advance that the management will only use the game for creating awareness. She emphasizes that if they would discover a real problem while playing, the management will need to take this problem into consideration. Awareness should not be the only outcome of the game, according to her, she also wants the management to use its output in the implementation of the future office environment.

- The game stimulates talking about behaviour.

Participants mainly talk about their behaviour in certain and specific situations, not about details regarding the layout of the new office. This could be explained by the fact that there already is a lot of clarity about the physical conditions of the new workplace. Questions about facts ("Can you do office work, like phoning, in a concentration cell?") and about rules ("Can your colleague leave his coat in the hallway, because he has no desk, however he has a locker?") are clear and do not need any discussion. Questions about personal feelings ("Two colleagues are chatting in an open work space, what do you think about this?") makes them talk about their own situation ("I would find it irritating, but I know I am a chatterbox too.") and they open up to each other. Players conclude that the game made them think about their present behaviour.

- The game stimulates talking about future behaviour.

Most questions more or less steer the discussion towards a present or future situation (e.g. "Imagine, the concentration-cell is always occupied by the time you arrive at the office, what do you do?"). Sometimes the participants mention that it is difficult to imagine how it could be in the future, but they solve this by focusing on how they value their own and others behaviour at present. They say that whatever changes in the physical layout of the office, the present behaviour should be maintained or avoided. They conclude that it is important to make a list of rules about the most simple situations and behaviour in these situations.

- The game stimulates talking about preferences concerning the future flexible office.

When the question describes a problem that can occur in the workplace and asks for a solution the group discusses about what they would like themselves and what they find irritating. They think of physical solutions for this problem that can cause this negative behaviour to turn positive. For example: "Meeting places for informal discussions are not used, how can you solve this problem?" They point out that the rooms are situated too far away from the workplaces, and that the chairs in the rooms are not suitable for discussions, but more for studying individually. They state that if the location and the interior of the rooms were more inviting and attractive, they would go there more often. 
Session 2 - Results of the observations. This session starts off a bit awkward, when one of the players does not seem to like to begin with the game, because the introduction of the workshop included a presentation of the design of the future office, which brought up many issues to deal with.

- The game stimulates talking about behaviour.

One participant wants to keep working the way he is working at present and he does not want to change his behaviour. After some questions he realizes that next to his own norms and values there are other people that you have to deal with in an open environment. He opens up a little, and says that he might has to adjust his behaviour in some situations, but he remains very sceptical about flexible offices.

- The game stimulates talking about future behaviour.

They discuss how situations are at present and project this to future situations. However, the employees have difficulties imagining how it would be like to work in an open office environment. The game made them realize that there obviously is a need for guidelines in the new environment. The current environment also has rules, but this behaviour seems more 'natural': no one ever thought about it. For the new environment different or additional rules must be developed to prevent workers from returning to their old habits and to stimulate them to make use of the new situation.

- The game stimulates talking about preferences for the future flexible office.

Players go into detailed descriptions of physical objects they want to have (e.g. "I want to have a place where I can plug in my water cooker.”). They start fantasizing about how they want their new office to be, especially in the discussion afterwards, when they have warmed up, the players start dreaming. Their enthusiasm however is slightly tempered by the presence of the architect. He mentions that the goal of this afternoon is to get to know the wishes of the employees, but he rejects many of their ideas. The main reason for this is that the basic layout and floor plan are already designed. It is obvious that the employees are disappointed that their opinion is asked too late in the design process. They want to convey their preferences for the work environment, but the things that are still to be decided and open for discussion are minimal (e.g. "How many whiteboards does your department need?"). The architect tries to convince the employees by talking about his own experiences, but he does not ask people why they want things or why they feel a certain way. For example, one person wants a cabinet of $1.80 \mathrm{~m}$ high, but it is not allowed to have higher cabinets than $1.20 \mathrm{~m}$. The interesting question here is why this person wants a cabinet of $1.80 \mathrm{~m}$ high: does he have prototype models of $1.80 \mathrm{~m}$ high? Does he have many documents to store? Or does he want privacy?

To conclude we could say that the Workplace Game stimulates employees to talk about their behaviour. The game makes players talk about their future work behaviour by eliciting information about their present work behaviour. The players extrapolate this knowledge about their likes and dislikes to the future and imagine how they would behave. The playing cards with questions trigger them to talk about their preferences for the future. Thus, the Workplace Game provides us with feelings of office workers in present situations ánd with dreams for future situations. 


\section{Discussion}

\subsection{Conclusion}

Looking back to Figure 1, one might say that the Workplace Game uses the interviewing technique to get information. Participants were asked questions, which they answered. To a certain extent this is true, however from the analysis we learned that people $d o$ talk about dreams and feelings about the new work situation, which is information from the deeper level of user knowledge. By playing the game the architect can reach a deeper understanding of the user, because tacit knowledge is brought up by revealing latent needs.

It can be concluded that the Workplace Game has elements of generative techniques. The questions themselves are an interviewing technique, but because of the way the questions are asked -by means of playing a game- they stimulate employees to dream about the future. Looking at literature about using games in design, games seem to be very useful in revealing unmet user needs. Games are helpful in creating a future vision, because they are structured, have explicit rules for participation and consist of carefully prepared activities. This makes the player feel engaged and the atmosphere informal, which allows players to communicate on the same level. Openended assignments, like the questions of the Workplace Game, give the participants opportunity to interpret and influence according to their own opinion; and gameboards and 3D pieces stimulate creativity [1], [2].

However, the Workplace Game does not provide directions for designing future flexible offices. This is mainly because the game is not aimed at generating ideas - it is designed as an evaluation and communication tool- so it does not stimulate creativity. But the main reason for the lack of creativity is that the game was played in a situation where the office design was almost completely determined. One participant mentioned that the game does not elicit what would be the most ideal workspace for herself, because it entailed the decision that was already taken of implementing flexible offices. Had the company not yet decided to take this direction, she might have expressed more latent needs and useful information for the architect. Other players wondered whether the moment the game was played is the right moment for playing, because it had already been decided that a flexible office would be their future. The architect who was present in the second session did not realize enough that he could still gain much inspiration from the employees, although he already designed much of the office; instead, he mainly defended his own design.

Looking at literature that integrates understanding user needs and creating new ideas, e.g. contextmapping, we can see that a specific structured process is followed. The aim of contextmapping is twofold: it is used to elicit user information and it is also concerned with bringing the information to the design team so that it can serve as inspiration for new design ideas [10]. The process that is followed stimulates this. First the user is warmed up by means of sensitizers (i.e. "participants are triggered, encouraged and motivated to think, reflect, wonder and explore aspects of their personal context in their own time and environment.") and after a week or so the individuals come together in a session in which the participants do generative exercises. The most useful information for the designer is a result of the sessions, since participants then start talking about the stories that are hidden behind the created artefacts. The generative exercises reveal people's knowledge, feelings, and dreams for the future. 
In the sessions with the Workplace Game we can conclude that the game functioned as a sensitizing tool, it warmed up the people and made them aware. The discussion afterwards however, could have given much more useful information to the architect. To a certain extent the discussion revealed interesting information, but it did not provide a more profound understanding of the employees.

\subsection{Recommendations}

If the Workplace Game were ever to be used as a helpful tool for designing future office spaces, three important recommendations for adapting it are discussed: the moment in the design process to play the game, the people that are involved in playing the game, and the product (the game) itself.

First of all, deciding on the moment to play the game in the design process (before, during, or after the design is made) is important for the results. When you want to engage employees in the process of changing a traditional office into a flexible office, it is important to involve them as soon as possible. At this time employees can still have the feeling that nothing has been decided and that they can fully participate in developing the future office space. The information that results from playing can be used by an architect or designer as a source of inspiration to create innovative flexible offices. On the contrary if the game is played after the flexible office is introduced the focus will lie more on evaluating and discussing behaviour. This results mainly in creating awareness amongst the employees and providing information about details for the architect.

Secondly, the people that are involved in playing the game have a large influence on the end result. Players in the first session mention that they are already open for innovative offices, because they are members of a board that is concerned with these changes. They think that their less open minded colleagues might have a more difficult time playing this game, because they will more often be confronted with new situations. However, these employees should also be consulted in a session of the game, because they can provide insight into why there is resistance. Also, when the architect of the flexible office is present he should be aware of his position. He should solicit employees more for their opinion and should be open to all kinds of input from them. The employees are to be considered as experts of their own experiences, and the architect is the expert on the design. Not all experiences can be implemented in the design, but an attempt should be made by the architect to listen more attentively to discussion between the employees and be creative with their wishes.

Thirdly, the Workplace Game itself, the product, has two elements that steers the information that results from the game session in a certain direction. First there are the playing cards that contain questions regarding present or future situations that steer the answers of the employees in a certain direction. When the architect focuses on discovering dreams for the future, it is important to find a good balance between present and future behaviour. It might prove to be useful to make the employees more aware of their changing behaviour by clearly separating the present and future and then making of using that by letting people compare the two situations, as far as possible. A second element that predetermines the game results is the consensus coin. We noticed that people often try to reach consensus, even though this is not necessary and differences in opinion are always allowed. When they focus too much on reaching 
consensus they might not express their individual dreams, and thus not provide the architect with adequate information about their latent needs. In a situation where players instantly agree on an answer, there is no group discussion, which means that if this situation takes place, the architect is also left with very little information.

\section{Future Research Focus}

Although the Workplace Game does seem to provide interesting information for the architect, further research is recommended if it is to be used for designing future office spaces. It could be interesting to do a case study with a group of employees at the start of the office change process. The employees should have some knowledge about the change and be interested in thinking about it, but there should not be a already determined office design. An architect could take part in the session to receive information, but he or she should be instructed to not be too critical, or possibly a moderator should be used that leads the discussion. This can reveal what information the game actually provides for architects and what information is not provided.

Another interesting focus for future research could be to use the Workplace Game as a sensitizing tool and develop a second Workplace Game which focuses on eliciting useful information for the architect to serve as inspiration for a future flexible office. Two questions come to mind: Does an architect wants to involve users in his design process, and, is a game the right format to elicit user information?

Acknowledgements. Thanks to the employees of an internationally operating company that creates innovative products and services in Life Sciences and Materials Sciences for participating in the case studies, and to Sanne Valkenburg for her help and advice with the analysis of the Workplace Game.

\section{References}

1. Brandt, E.: Designing exploratory design games: a framework for participation in Participatory Design? In: $9^{\text {th }}$ Conf. on Participatory Design: Expanding Boundaries in Design, Trento, Italy, August 01-05, 2006, pp. 57-66. ACM Press, New York (2006)

2. Brandt, E., Messeter, J.: Facilitating Collaboration through Design Games. In: $8^{\text {th }}$ Conference on Participatory Design: Artful Integration: Interweaving Media, Materials and Practices, Toronto, Ontario, Canada, July 27-31, pp. 121-131. ACM Press, New York (2004)

3. De Bruyne, E., De Jong, A.: The Workplace Game: Exploring End Users' New Behaviour. In: Applied Human Factors and Ergonomics 2008 Int. Conf., Las Vegas (2008)

4. De Jong, A., De Bruyne, E.: Participatory design of office spaces by game playing? In: Applied Human Factors and Ergonomics 2008 Int. Conf., Las Vegas (2008)

5. Fulton Suri, J.: Empathic Design: Informed and Inspired by Other People's Experience. In: Koskinen, I., Battarbee, K., Mattelmäki, T. (eds.) Empathic Design, User Experience in Product Design, pp. 51-57. IT Press, Helsinki (2003)

6. Koskinen, I.: Empathic Design in Methodic Terms. In: Koskinen, I., Battarbee, K., Mattelmäki, T. (eds.) Empathic Design, User Experience in Product Design, pp. 59-65. IT Press, Helsinki (2003) 
7. Koskinen, I., Battarbee, K.: Introduction to User Experience and Empathic Design. In: Koskinen, I., Battarbee, K., Mattelmäki, T. (eds.) Empathic Design, User Experience in Product Design, pp. 37-50. IT Press, Helsinki (2003)

8. Sanders, E.B.-N.: Postdesign and Participatory Culture. In: Useful and Critical: The Position of Research in Design, University of Art and Design, Tuusala, Finland, September 9-11, pp. 87-92 (1999)

9. Sanders, E.B.-N., Dandavate, U.: Design for Experiencing: New Tools. In: Proceedings of the $1^{\text {st }}$ International Conference on Design and Emotion. University of Technology, Delft (1999)

10. Sleeswijk Visser, F., Stappers, P.J., Van der Lugt, R., Sanders, E.B.N.: Contextmapping: Experiences from Practice. CoDesign 1(2), 119-149 (2005) 